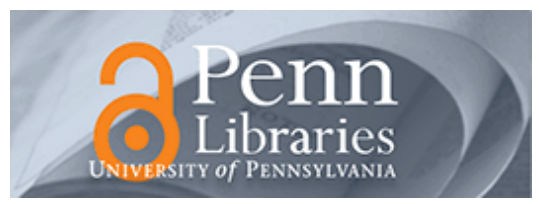

University of Pennsylvania

ScholarlyCommons

Accounting Papers

Wharton Faculty Research

$12-2003$

\title{
Testing the Relative Power of Accounting Standards Versus \\ Incentives and Other Institutional Features to Influence the Outcome of Financial Reporting in an International Setting
}

Robert W. Holthausen

University of Pennsylvania

Follow this and additional works at: https://repository.upenn.edu/accounting_papers

Part of the Accounting Commons, and the International Business Commons

\section{Recommended Citation}

Holthausen, R. W. (2003). Testing the Relative Power of Accounting Standards Versus Incentives and Other Institutional Features to Influence the Outcome of Financial Reporting in an International Setting. Journal of Accounting and Economics, 36 (1-3), 271-283. http://dx.doi.org/10.1016/ j.jacceco.2003.10.004

This paper is posted at ScholarlyCommons. https://repository.upenn.edu/accounting_papers/41

For more information, please contact repository@pobox.upenn.edu. 


\title{
Testing the Relative Power of Accounting Standards Versus Incentives and Other Institutional Features to Influence the Outcome of Financial Reporting in an International Setting
}

\author{
Abstract \\ Ball, Robin and Wu (Journal of Accounting and Economics, 2003, this issue) investigate the relationship \\ between accounting standards and the structure of other institutions on the attributes of the financial \\ reporting system. They find evidence consistent with the hypothesis that beyond accounting standards, \\ the structure of other institutions, such as incentives of preparers and auditors, enforcement mechanisms \\ and ownership structure affects the outcome of the financial reporting system. However, interpretation of \\ the evidence with respect to the notion of quality of the financial reporting system and the quality of \\ accounting standards that the authors introduce is problematic.

\section{Keywords} \\ financial reporting quality, international accounting standards, cross-country comparisons, transparency, \\ timeliness, conservatism, economic income \\ Disciplines \\ Accounting | International Business
}




\title{
Testing the Relative Power of Accounting Standards versus Incentives and Other Institutional Features to Influence the Outcome of Financial Reporting in an International Setting
}

\author{
by \\ Robert W. Holthausen \\ Wharton School \\ University of Pennsylvania \\ Philadelphia, PA 19104 \\ holthausen@wharton.upenn.edu \\ $215898-7781$
}

October 17, 2003

This paper is based on my discussion comments of "Incentives versus Standards: Properties of Accounting Income in Four East Asian Countries" by Ray Ball, Ashok Robin and Joanna Wu which was presented at the October, 2002 Journal of Accounting and Economics conference. I would like to thank Doug Skinner and Ross Watts for comments. I am particularly indebted to my colleague Christian Leuz for numerous informative discussions about this topic. All misdeeds are, of course, my own.

\begin{abstract}
Ball Robin and Wu (2003) investigate the relationship between accounting standards and the structure of other institutions on the attributes of the financial reporting system. They find evidence consistent with the hypothesis that beyond accounting standards, the structure of other institutions, such as incentives of preparers and auditors, enforcement mechanisms and ownership structure affects the outcome of the financial reporting system. However, interpretation of the evidence with respect to the notion of quality of the financial reporting system and the quality of accounting standards that the authors introduce is problematic.
\end{abstract}

JEL Classification: D82; F02; G15; M41; 053

Keywords : Financial Reporting Quality; International Accounting Standards; Cross-Country

Comparisons; Transparency; Timeliness; Conservatism; Economic Income 


\section{Introduction}

The major contention of Ball, Robin and Wu (2003) (henceforth BRW) is that accounting standards alone do not determine the quality of financial statements and financial reporting. Beyond accounting standards, incentives of preparers and auditors, enforcement mechanisms, ownership structure and other institutional features of the economy affect the outcome of the financial reporting process.

BRW contend that the East Asian countries of Hong Kong, Malaysia, Singapore and Thailand are a good setting for testing the premise that high quality standards are a key determinant of financial reporting quality. They argue that these four countries have high quality standards (heavily UK, US and IAS influenced) but have institutional structures that provide incentives to issue low-quality reports. Hence, they predict that the outcome of the overall structure in those countries will lead to low quality financial reporting.

In order to conduct any empirical work toward their stated goal, BRW must operationalize the concept of the quality of the financial reporting system. Their measure is the timeliness with which economic income is reflected in accounting income, where economic income is defined as the common stock return over the fiscal year of a company. Within that framework, they further concentrate on the extent to which the accounting system recognizes economic losses on a timely basis, i.e., conservatism. Thus, the empirical tests generally entail various regression specifications of net income on common stock returns.

The evidence in BRW is not consistent with timely recognition of economic income (particularly losses) in the four East Asian countries despite their alleged high 
quality standards. The results indicate that the earnings timeliness of the four East Asian countries is more similar to code than common law countries. Hong Kong's financial reporting is the most timely of the four East Asian countries, consistent with its market orientation, while Thailand's is the least timely, consistent with the influence of tax and government codification of standards in that country. The results are consistent with incentives of preparers and other institutional factors having a first-order effect on the outcome of the financial reporting process.

The authors argue that their results have three interesting implications. First, the literature's focus on the "quality" of accounting standards per se is an incomplete and potentially misleading classification scheme for determining the quality of a country's financial reporting. Second, they argue that if a country wants to increase its financial reporting quality, changing manager and auditor incentives and other institutional features is more important than mandating foreign accounting standards. Third, they argue that pressure to reduce variation in accounting standards across countries will not resolve differences in the quality of financial reporting across countries, unless other important features that influence the reporting process are also changed. Moreover, adoption of IAS standards by countries with weak incentives and enforcement mechanisms will likely lead to damaging the perceived quality of IAS standards.

My discussion comments will focus on six issues. I conclude with a summary and discussion of future potential work. 


\section{Is this an interesting and important question?}

There is little doubt that determining the marginal effects of accounting standards, incentives, ownership structure, institutional features of the capital markets and enforcement on the quality of financial reporting is an interesting and important issue. The general theme of the paper relates to many interesting and important issues. Are accounting standards and other institutional features complements or substitutes? Are there alternative mechanisms for achieving a particular level of quality in the financial reporting system, that is, are there a variety of structures that can result in equivalent outcomes? Which institutional features are most important, which are least important? Is it easier for firms to opt out of their country's poor reporting environment to raise outside capital if there are high quality standards available than if there are only low quality standards. Many have now contributed to this general area of inquiry and some of the already-published work was influenced by earlier drafts of BRW. Irrespective of my subsequent critiques of their paper, BRW's contribution to this literature is obvious.

\section{Is this a good setting to address the interplay of accounting standards and}

\section{other institutional features? Or, are IAS Standards of high quality?}

A crucial assumption of BRW's tests is that the IAS standards as adopted by these East Asian countries are of "sufficiently" high quality. If they are not of high quality, then it is not obvious that the authors can legitimately draw any conclusion about the relative power of accounting standards and other institutional features to affect the outcome of the financial reporting process. The question is whether there must be some minimal quality level reached by the accounting standards in order for those standards to 
substitute for certain institutional features. If the standards were of only mediocre quality, then we may have learned little about whether standards can substitute for other institutional features and impact the quality of financial reporting. Moreover, it would be difficult to conclude that future attempts to homogenize accounting standards around the world using IAS will lead to similarly poor outcomes for the financial reporting process as seen in these tests on Asia, especially if IAS standards have improved or continue to improve. As such, the authors must assume some minimum quality threshold was met during their sample period in order to draw their conclusions.

The authors' stated rationale for why these standards are of high quality relates both to the IAS standards themselves as well as to the common law influence on the standards adopted in these four East Asian countries. However, a key question is whether the accounting standards in these four Asian countries were of high quality during the time period of the authors' tests. Consider the following abbreviated history. The IASC was founded in 1973 to set international accounting standards. Starting in 1987, the IASC undertook the Comparability/Improvements Project and the resulting standards became effective in 1995 . This project was undertaken because of a multitude of perceived deficiencies in IAS. In July, 1995, the IASC and IOSCO agreed on a list of further important issues that needed to be addressed. This "Core Standards Project" led to substantial revisions in IAS and those were completed (except for one) by March, 1999, after the time period of the data for this study (1984-1996).

Thus, if current or future IAS standards are of higher quality than the quality of the IAS standards during the authors' sample period, there is no way to know from the evidence in this paper whether the standards have become strong enough to mitigate the 
effect of other institutional features that might lead to lower quality financial reporting. Nor can we know from the evidence in BRW, whether accounting standards can become strong enough to mitigate the effects of certain institutional features. Thus, it is difficult to infer the potential effects of further adoption of IAS.

There is some evidence which is consistent with the hypothesis that IAS standards have improved. Leuz and Verrecchia (2000) show, albeit in a small sample, that early adopters of IAS from German GAAP received relatively little decrease in bid-ask spreads and little increase in volume relative to later IAS adopters from German GAAP. This is consistent with IAS standards increasing in quality through time.

In a letter to the editors, BRW provided information about the early (1984 - 1991) vs. later period (1992-1996) and report qualitatively similar findings in that the Asian group still looks more like the code-law group than the common-law group in both subperiods. However, those tests also show an increasing $\mathrm{R}^{2}$ between the first and second period and an increase in the timely recognition of losses in the second sub-period for the East Asian countries. The authors did not provide tests on whether the increases are significant, but judging from the results, the increase in the timely recognition of losses may well be significant. Thus, it appears that a shift in the characteristics of the financial reporting process was taking place between the first and second sub-period. Whether that is due to a shift in IAS standards or whether it was due to shifts in other institutional features cannot be determined from this evidence. ${ }^{1}$ We do know, however, that IAS standards were evolving during this time period. So the question remains, were the

\footnotetext{
${ }^{1}$ As I explain later, this finding could also have nothing to do with changes in a country's accounting standards or institutions. Instead, it could be driven by firms choosing to at least partially opt out of their country's accounting and institutional structure by cross-listing in other capital markets or using other appropriate mechanisms.
} 
standards of sufficiently high quality even in the second sub-period? If not, it is difficult to draw conclusions from the evidence about the relative power of high-quality standards and other institutional features.

Leuz (2003) examines various liquidity and information asymmetry variables for German firms that list on the New Market and who must adopt either IAS or U.S. GAAP in order to be listed. The salient feature of this paper is that the institutional structure is held reasonably constant because he examines only German firms that adopt U.S. or IAS GAAP with no other regulatory change. No differences in information asymmetry or liquidity were found between German firms adopting IAS GAAP and those adopting U.S. GAAP. The time period of the data for the Leuz study is after the Core Standards project for IAS, whereas the BRW data is all from a prior period. Given no observed differences in information asymmetry or liquidity between German firms that adopt U.S. or IAS GAAP, there are two potential interpretations. One interpretation is that the standards had increased sufficiently in quality after the Core Standards project to eliminate any differences in liquidity or information asymmetry that might have been observable previously. This would be consistent with standards having a first-order effect. The alternative interpretation, consistent with $\mathrm{BRW}$, is that since the institutions are held relatively constant in this experiment but the standards vary at least to some degree, standards matter little and institutions matter a great deal. Unfortunately, the setting does not allow us to determine which of the two alternative explanations is correct. 


\section{Qualitative vs. Quantitative Country Descriptions}

BRW's predictions about the four East Asian countries relative to code or common law countries are qualitative in nature. Their arguments are similar to the qualitative standard established in Ball, Kothari and Robin (2000) (henceforth BKR). While there is nothing wrong with qualitative arguments, especially in new fields, it would have moved the literature a step forward if they had pushed harder on the measurement issues in this paper instead of adopting the standard of BKR.

As an example of a more quantitative approach to characterizing countries' institutions, Leuz, Nanda and Wysocki (2003), henceforth LNW, perform a cluster analysis on nine institutional variables discussed in La Porta, Lopez-de-Silances, Shleifer and Vishny $(1998,1999,2000)$. These variables include features like investor rights, legal enforcement, outsider or insider economy, stock market size, etc. From their cluster analysis, LNW identify three different types of economies. The first is outsider economies with large stock markets, dispersed ownership, strong investor rights and strong legal enforcement (Singapore, Hong Kong, Malaysia, UK, Norway, Canada, Australia and USA are in this cluster). The second is insider economies with less welldeveloped stock markets, concentrated ownership, weak investor rights, but strong legal enforcement (Austria, Taiwan, Germany, Switzerland, France and Sweden are in this cluster). The third is similar to the insider economy described above, but with weak legal enforcement (Thailand, Greece, Korea, Spain and India are in this cluster).

LNW then examine the extent to which earnings management is correlated with a country's institutional characteristics. They find increasing earnings management as they move from cluster one to cluster three. Interestingly, consistent with BRW, they find 
more earnings management in Hong Kong, Singapore and Malaysia than any other country in the first cluster. Thus, the results of LNW lend some support to BRW's qualitative analysis. However, LNW's results also suggest that these four East Asian countries are not homogeneous, and that Thailand is different from the others.

An approach like LNW seems like a reasonable quantitative start, though certainly not the only type of empirical analysis that could be conducted. In addition, if one were to adopt such an approach for the BRW paper, there may well be additional institutional features that need to be considered given the questions addressed by BRW. For example, a variable that captures the ownership structure issues discussed by BRW might be an important addition. ${ }^{2}$ Such additional characteristics might separate Hong, Kong, Malaysia and Singapore from the other countries in the first cluster or perhaps rank order the Asian countries on the extent to which we would expect earnings to be informative.

My point is not that the qualitative arguments of BRW are wrong, but since they are close in spirit to the types of arguments in BKR, it would be useful for the literature to begin to try to structure and quantify these differences using more quantitative measures and methodologies. Moreover, I am not suggesting that the approach used by LNW is the only approach that one could take. I'm merely suggesting that BRW could have pushed harder to develop potentially more informative tests that have at least the potential to provide additional insights and structure. I note, that the literature as a whole appears to be moving in that direction.

\footnotetext{
${ }^{2}$ See Claessens, Djankov and Lang (2000) for a detailed discussion of the ownership structure and the separation of control and cash flow rights in East Asia.
} 


\section{Are the Four Asian Countries Homogeneous?}

The authors, for the most part, treat the four Asian countries as being homogeneous, despite their discussions and the evidence of others that suggests these countries are not homogeneous. Table 3 of BRW contains the only test for significant differences across countries anywhere in the paper and it reports differences between groups of Asian, common and code countries. For both Asian and common countries, BRW show that earnings increases are less timely than for code countries, while loss recognition for the Asian countries is insignificantly different from code countries and both are less timely than losses for common countries.

The central question here is why treat these countries homogeneously. BRW actually provide a rationale for why Thailand, at a minimum, should be treated differently from Hong Kong, Singapore and Malaysia. Moreover, the cluster analysis of LNW is consistent with at least classifying Thailand separately. Looking at BRW's figure 1, it is not obvious that these countries are homogeneous. Unfortunately, the authors provide no formal tests for whether the four Asian countries are significantly different from one another.

To the extent the authors rely on $\mathrm{R}^{2} \mathrm{~s}$ of pooled country regressions (code, common and Asian), differences in the degree of heterogeneity across countries will affect the regression $R^{2} s$, since all countries within a group are forced to have the same slope coefficients. Also implicitly, there is an assumption that the slope coefficients across firms within country are similar as well. If some countries have predominantly high- tech firms and some have predominantly low-tech firms, countries could experience different $R^{2} s$ and slope coefficients simply because of the informativeness of earnings 
with respect to the mix of industries represented, even if the accounting standards and other institutions supporting the financial reporting process were identical across countries. BRW attempt to deal with the latter issue by including some industry dummy variables in the regression as a sensitivity analysis.

\subsection{Is Economic Income Measured with the Same Accuracy Across Countries?}

BRW's price tests assume that stock returns capture the same degree of "true economic income" across countries. That is, since stock returns are BRW's measure of "true economic income", they are assuming that stock returns capture "true economic income" equally well across countries using one-year windows. Moreover, they are assuming that good and bad news are reflected equally in stock returns within those oneyear windows. Thus, irrespective of the reporting environment, stock price returns are assumed to capture economic income equivalently across countries, an assumption that BRW discuss explicitly.

BRW argue that insider knowledge would likely lead to the capture of equivalent economic income, even in places where the countries are essentially "insider economies" with limited disclosure requirements. But why do insiders in these "insider economies" have the same incentives to trade as a well-informed trader in a more market oriented economy? Do insiders have incentives to drive down stock prices in the face of bad news or increase stock prices in the face of good news if their equity positions are basically permanent? If these are family-owned businesses, how much trading should we expect to see and is that level of trading sufficient to incorporate insiders' information? Moreover, insiders' incentives to reveal good or bad information may shift through time 
if there are periods where they are raising or retiring outside capital. If insiders don't have the same incentives to reveal good and bad news in their trading or through disclosure, biases might exist in the tests of timeliness and conservatism if stock returns don't reflect economic events equally quickly across countries or if good news and bad news are not reflected equally rapidly in stock returns.

There is evidence to suggest that the informativeness of stock prices is not uniform across countries. Morck, Yeung and Yu (2000) show that synchronicity in stock returns is related to variables that measure government respect for private property and the extent of protection of public shareholders' property rights against corporate insiders. Lower synchronicity means that relatively more firm-specific information is capitalized into stock prices while higher synchronicity means that firm valuations are based relatively more on overall economic news. Morck, Yeung and Yu (2000) rank 40 countries on the extent of the synchronicity in stock prices where a rank of one denotes the highest degree of synchronicity. Using two different measures of synchronicity, Malaysia ranks third (fourth), Thailand eighth (seventeenth), Singapore fifteenth (eleventh) and Hong Kong twenty-third (sixteenth). The United States ranks fortieth on both dimensions with many other common law countries ranking close to the United States. Thus, there is wide dispersion across countries in general and the four East Asian countries in particular, with respect to how much firm-specific information is capitalized into prices. The evidence on synchronicity is consistent with expecting the four East Asian Countries to exhibit $R^{2} s$ and potentially slope coefficients that look more like code 
countries than common countries simply because of differences in the ability of stock returns to capture "true economic income". 3

In discussing the impact of political costs on reported accounting numbers, BRW indicate that the Chinese are minorities in some of the East Asian countries, but represent many of the dominant family groups with substantive holdings. BRW argue that because the Chinese are subject to discrimination or potential discrimination in some of these countries, they do not want to disclose either extreme good or bad accounting performance because it is possible that the governments in those countries might choose to expropriate their wealth. BRW offer this as one explanation for why the link between economic and accounting income may be weak in the East Asian countries. But this argument seems incomplete because it focuses only on the manipulation of accounting income. If the Chinese-insider families are worried about wealth expropriation, would they buy shares in their corporations based on good news that only they knew, hence driving up the price because of their trades? If wealth expropriation is of concern, it would seem that they would be at least as concerned with managing the stock price, not just earnings, especially if their holdings are relatively permanent. If these insiders are not trading on their inside information, it is much less obvious that stock prices measure "true economic income" with the same degree of precision across countries.

To their credit, BRW do incorporate some non-price tests in the paper to alleviate concerns about the extent to which stock prices capture economic income equivalently across countries. Those results are consistent with the price-based tests and mitigate this

\footnotetext{
${ }^{3}$ The evidence in Morck, Yeung and Yu (2000) uses biweekly holding periods to measure synchronicity. So while informative, their research does not speak directly to the experimental design in BRW as BRW use annual return windows. Nevertheless, the evidence on synchronicity is certainly consistent with the notion that economic income, as defined by BRW, may not be measured identically across countries.
} 
concern. Nevertheless reliance on stock prices for examination of issues of this type is something that the literature should evaluate carefully. Evidence examining the extent to which stock prices reflect economic income equally across countries would be beneficial in trying to correctly specify tests in this area. In addition, reliance on non-price tests is potentially extremely useful and it would behoove us to understand more about the size and power of those types of tests.

\section{What is the extent of a timeliness and conservatism in a high quality financial} reporting system?

There is a degree of circularity in BRW's research design that gets introduced into their study because of the "high quality" and "low quality" labels that appear in the paper. If the word quality did not appear in the paper, the paper would test whether institutional structures beyond accounting standards affect the characteristics of the financial reporting system. BRW would measure timeliness and conservatism (two measurable outcomes of the financial reporting system) and show that holding standards relatively constant (East Asian vs. Common in their view), we observe that timeliness and conservatism are different across institutional structures (East Asian vs. Common).

So how does the use of the word quality affect their paper? First, they have to decide which countries have formal accounting standards which are high quality and which have low quality. This definition of quality seems to come from the commonly held belief among many writers in the international arena, that U.S., U.K. and IAS accounting standards (common-law influenced) are of high quality while many other standards (code-law influenced) are of low quality (Japan and Germany, at least 
historically). I have already questioned whether the IAS standards in the time period of the study are of sufficiently high quality, but this is not where the circularity in their study occurs.

The circularity occurs from equating the timeliness and particularly the conservatism observed in the U.S. and other common-law countries with quality. Assume the authors' premise, that other institutions beyond accounting standards affect timeliness and conservatism, is correct (which I believe it is). Then it is circular to judge the quality of financial reporting by the degree of timeliness and conservatism observed in common law countries. So even if we all agreed that U.S. GAAP was of the highest quality, judging the quality of other countries financial reporting regimes by a standard of U.S. timeliness and conservatism would not be warranted.

BRW discuss why we expect to see conservatism in financial reporting (e.g., debt contracts, monitoring, litigation, etc.). Prior evidence is consistent with the litigation environment in the United States impacting the asymmetry in the recognition of gains and losses in the financial reporting process. Both Basu (1997) and Holthausen and Watts (2001) find evidence consistent with the litigation environment affecting the extent of conservatism. But which is better, the extent of gain and loss recognition in the United States or in Hong Kong? BRW's results on Hong Kong look strikingly like Holthausen and Watts' results for the United States pre 1983.

The question is what level of conservatism is consistent with high quality financial reporting? It isn't at all obvious that the degree of conservatism observed in the United States, Canada and Australia in the recent past implies a high quality financial reporting process, since the outcome in those countries is likely affected by the extensive 
litigation environment. Thus, it is not apparent that the degree of conservatism in the United States or other common law countries is an appropriate benchmark for quality. Moreover, it is likely that different users would prefer to see varying levels of conservatism within a country given their particular use of financial statements.

Thus, the authors' main premise may well be correct -- institutions can affect the attributes of the financial reporting process despite high quality accounting standards. However, there is circularity in attempting to determine whether IAS standards as applied in the four East Asian countries resulted in a "low quality outcome" (see p. 1 of BRW), by comparing the timeliness and conservatism of the four East Asian countries to that observed in common law countries. Who is to say, or know, whether the observed common-law outcome is "high quality"? There is no theory of which I am aware that can equate quality with the degree of timeliness and conservatism observed in the United States and other common-law countries.

Thus, I believe that the authors are on fairly "safe ground" with respect to investigating the relative impact of accounting standards and other features of the institutional structure on characteristics of the financial reporting process (in their case timeliness and conservatism), subject to the caveat that economic income may not be measured equivalently across countries. However, I think the introduction of the word "quality" in the paper leads to potential interpretation issues and introduces circularity into the paper.

There is another related point that is worth making here. Certainly it is likely that financial reporting systems (standards, incentives, legal regimes, etc.) evolve to fit the economies they support. Perhaps those structures evolve too slowly, as some have 
indicated. Nevertheless, it is important to recognize that this study does not speak to whether a particular reporting regime is appropriate for all countries (and the authors are careful not to make that claim). So even though the word quality is used in the paper, the authors do not claim that a high quality financial reporting process, as they define it in terms of timeliness and conservatism, would be optimal for all economies. However, my fear is that some readers may be confused on that point because of the introduction of the concept of quality in the paper.

\subsection{Summary and Future Work}

So in summary there are both positive and negative aspects of this paper. On the positive side, the topic is interesting. It is believable and interesting that country-specific institutions beyond standards affect the characteristics of the financial reporting process, and I expect that future empirical work will be consistent with that premise. Thus the authors have certainly made a contribution, especially to the extent that some in the international arena have equated the quality of the financial reporting process with the quality of the formal standards alone. The authors have demonstrated the importance of considering the entire institutional structure on the financial reporting process.

This issue is also important because it points to the difficulty of attempting to judge accounting standards through stock price studies, as those tests reflect both the accounting standards and the institutions of a country. In Holthausen and Watts (2001), we critiqued the value relevance studies which attempt to shed light on the choice among alternative accounting standards by examining associations between stock prices and alternative accounting numbers. Among other critiques of that literature, we made the 
point that the observed associations are influenced by the institutional structure as well, so the outcome of that empirical work is not driven purely by accounting standards alone. Hence, those tests reflect more than the characteristics of accounting standards.

On the negative side, there are interpretational difficulties associated with this study. While the authors provide evidence consistent with the notion that standards alone do not determine the outcome of the financial reporting process, it is less clear that they have provided evidence about whether "high quality" standards are a first-order effect or not, as there is uncertainty about whether the IAS standards are of high quality during this time period.

Perhaps international comparisons are not the most powerful tests of the hypothesis that institutional structures beyond accounting standards affect the characteristics of financial reporting because there are so many things that are difficult to adequately control for in cross-country work. The trade-off of course, is that there are greater differences in institutional structures across countries. As an alternative, there may be within country changes in standards or institutions that would isolate certain effects better than a cross-country comparison. In this case, we may be able to hold more features of the overall reporting regime constant in the experiment than we can when making cross-country comparisons. ${ }^{4}$ To the extent we can find natural experiments where fewer things are changing, we may be able to get a handle on which institutions are more important determinants of the financial reporting process and whether accounting standards can substitute for some institutional features but not others.

\footnotetext{
${ }^{4}$ Leuz (2003), on the choice of IAS or US GAAP for New Market firms in Germany, is an example of a study that tries to hold the institutional arrangement constant and varies the accounting standards.
} 
Complicating the authors' quality interpretation is the question of what is the appropriate benchmark for high quality financial reporting. How much conservatism is too much and how quickly should economic gains and losses be recognized? Is the outcome of the financial reporting process in the United States a high quality one? Is it high quality to all constituencies? The answers to these questions are not readily apparent based on the timeliness and extent of asymmetry between gains and losses observed in the United States and in other common-law countries. While it is undoubtedly safe to say that the outcome of that financial reporting process responds to incentives, institutions and accounting standards, it is much more difficult to say what outcomes are high quality and what outcomes are low quality.

With respect to future work, I would hope the literature evolves tow ard a more quantitative approach to classifying the countries. In the context of the current paper, I would have preferred to have seen tests of whether the Asian countries should be treated as a homogeneous group and, if that hypothesis were rejected, to use some empiricallydriven approach to classifying the East Asian countries. Those differences could then be used to develop potentially more powerful tests.

To the extent that the literature continues to rely on stock prices to measure economic income, it is paramount that we document the extent to which stock returns capture "true economic income" equally across countries and the extent to which good and bad economic news is reflected equally quickly in stock returns across countries. We also need to better understand the power and size of non-price tests which might serve as useful substitutes for stock return tests. 
It is also likely to be productive to not treat firms homogenously within country. For example, to what extent can firms opt out of their country's reporting regime? If reporting regimes arise to balance all the forces in an economy, it is likely that a particular country's financial reporting regime isn't equally optimal for all firms in a particular economy. For example, in an insider economy dominated by banks and large families, there will be some firms that will find it advantageous to raise capital from equity investors. Can they opt out of their reporting regime by cross-listing ${ }^{5}$, by hiring a high quality auditor ${ }^{6}$ or some other mechanism? If many firms in a given economy choose some mechanism to opt out of their country's normal financial reporting regime, then the results of tests like BRW will be a weighted average of all firms in the economy, those opting out and those not.

This suggests that we may want to refine the types of tests that are conducted in some cross-country comparisons and allow for differences between firms within country. This is potentially important because it may be possible to undo or mitigate the effects of incentives and other forces, conditional on having adequate standards to begin with. If so, standards could still play a pivotal role in economies like those studied here, even if on average, the institutions don't support them. As such, it would be premature to assume that adopting high quality standards could not lead to better outcomes for those firms which would like to opt out of a generally low quality reporting environment.

\footnotetext{
${ }^{5}$ Doidge, Karolyi and Stulz (2003) show that non-U.S. firms listing in the U.S. have Tobin's q ratios that exceed that of their home country counterparts by $16.5 \%$. They argue that non-U.S. firms which list in the U.S. do so because the benefits to the controlling shareholders from being able to take advantage of their growth opportunities exceeds the loss from giving up their private control benefits. Thus, firms which choose to list in the U.S. have greater growth opportunities than those who do not. Hence, these firms opt out of their country's institutional structure, at least in part.

${ }^{6}$ Fan and Wong (2001) provide evidence that in eight East Asian countries where conventional corporate control mechanisms are not operative (the market for corporate control, independent boards, etc), that high quality auditors do provide a monitoring and bonding mechanism to alleviate agency conflicts.
} 
For example, perhaps a firm can opt out of a poor reporting regime by choosing a high quality auditor, conditional on there being high quality standards in place. But, if the standards are not of high quality, than perhaps hiring a high quality auditor cannot rectify the poor reporting regime. So standards could matter a great deal, but one might not see it in aggregate tests of the type conducted in BRW. Examining variation across firms might allow us to determine the extent to which accounting standards and other institutional features are complements or substitutes.

The notion that firms can opt out of their country's institutional arrangements has implications for other work in this area. For example, apparent "improvements" in financial reporting as measured by metrics like timeliness and conservatism could be due more to firms opting out of their country's institutional arrangements than to changes in accounting standards or changes in a country's institutions. For example, if more of a country's firms go to international capital markets (say, the U.S. capital markets) at the same time as that country adopts IAS, it might appear that IAS is affecting financial reporting. However, an equally plausible explanation might be that it is the act of opting out of the country's institutional structure that is the cause. This suggests that we should try to control for or eliminate firms that cross-list or which take other steps to mitigate the features of their institutional structure.

Despite my specific critiques of this paper, I believe this is an interesting and provocative line of inquiry and an important issue for future research. Moreover, I believe that the BRW paper is an important part of this line of research. Readers are warned, however, to interpret the "quality" labels used by BRW with great care. 


\section{References}

Ball, R., S. Kothari, A. Robin, 2000. The effect of international institutional factors on properties of accounting earnings. Journal of Accounting and Economics 29, 1-52.

Ball, R., A. Robin and J. Wu, 2003. Incentives versus standards: Properties of accounting income in four East Asian Countries. Jourrnal of Accounting and Economics, this issue.

Basu, S. 1997. The conservatism principle and the asymmetric timeliness of earnings. Journal of Accounting and Economics 24, 3-37.

Claessens, S., S. Djankov and L. Lang, 2000. The separation of ownership and control in East Asian Corporations. Journal of Financial Economics 58, 81-112.

Doidge, C. G. Karolyi, and R. Stulz, 2003. Why are foreign firms listed in the U.S. worth more? forthcoming Journal of Financial Economics.

Fan, J., T. Wong, 2001. Corporate ownership structure and the informativeness of accounting earnings in East Asia. Journal of Accounting and Economics 33, 401-426.

Holthausen, R., and R. Watts, 2001. The relevance of the value relevance literature for financial accounting standard setting." Journal of Accounting and Economics 31, 3-77.

La Porta, R., F. Lopez-de-Silanes, A. Shleifer, R. Vishny, 1998. Law and finance. Journal of Political Economy 106, 1113-1155.

La Porta, R., F. Lopez-de-Silanes, A. Shleifer, R. Vishny, 1999. Corporate ownership around the world. Journal of Finance 54, 471-517.

La Porta, R., F. Lopez-de-Silanes, A. Shleifer, R. Vishny, 2000. Investor protection and corporate governance. Journal of Financial Economics 58, 3-27.

Leuz, C. 2003. IAS versus U.S. GAAP: Information asymmetry-based evidence from Germany's New Market. Journal of Accounting Research 41, 445-472.

Leuz, C., D.J. Nanda and P. Wysocki, 2003. Earnings Management and Investor Protection: An International Comparison. Journal of Financial Economics 69, $505-$ 527.

Leuz, C. and R.Verrecchia, 2000. The economic consequences of increased disclosure. Journal of Accounting Research 38, 91-124.

Morck, R. B. Yeung and W. Yu, 2000. The information content of stock markets: Why do emerging markets have synchronous stock price movements? Journal of Financial Economics 58, 215-260. 